\title{
Safety Leadership Defined within the Australian Construction Industry
}

\author{
Luke Daniel \\ School of Business and Tourism, Southern Cross University, Australia
}

\begin{abstract}
This research explores the tenets of safety leadership within the Australian construction environment. The scope of this research aims to establish a universal definition of safety leadership and how it differs from other leadership disciplines. The literature review into this topic was governed by the parent disciplines of Safety and Leadership. Gaps were identified in the literature that indicated safety leadership is not a well-defined concept and much of the work into safety leadership has been borrowed from other schools of leadership. An exploratory research methodology was utilised which rooted the research into the post-positivist methodology. There were twenty interviews conducted for this research, with participants coming from various leadership positions across multiple construction projects around Australia. Findings detailed a saturation of data that allowed for an empirical definition towards safety leadership to be established. As a person's scope of responsibility increases, their view of safety leadership becomes synonymous with leadership; although differences do exist. These differences were attributed to the importance of demonstrating safety and working within the legal framework of Australian construction projects. It is proposed that this research offers a substantial contribution to knowledge, based upon a well-defined definition into safety leadership.
\end{abstract}

Keywords: Safety leadership, construction, definition, behaviour, Australia.

Paper type: Research article

\section{Introduction}

Safety leadership within itself is a concept that borrows heavily from the leadership framework with specifics being based upon transformational leadership (Mullen and Kelloway, 2009). Throughout this research, safety leadership will be explored and defined with the main research question being framed as: How do leaders within the construction environment define safety leadership and how does safety leadership differ from other leadership disciplines?

This research has been rooted within the Australian construction industry due to the considerable size of the industry and challenges that pertain to its specificity. These challenges within the construction project environment include personal commitment and responsibility towards safety, communication and organisational culture (Hashim and Chileshe, 2012).

A well-constructed definition towards safety leadership can enhance consistency and minimise confusion around the topic as well as rooting safety leadership within the leadership literature. Without a clear definition towards safety leadership, a misalignment between safety expectations may occur which can create a misappropriation towards safety efforts. This may adversely impact

\footnotetext{
Copyright: Construction Economics and Building 2015. (C) 2015 Luke Daniel. This is an Open Access article distributed under the terms of the Creative Commons Attribution 4.0 Unported (CC BY 4.0) License (https://creativecommons.org/licenses/by/4.0/), allowing third parties to copy and redistribute the material in any medium or format and to remix, transform, and build upon the material for any purpose, even commercially, provided the original work is properly cited and states its license.
}

Citation: Daniel, L., 2015. Safety leadership defined within the Australian construction industry, Construction Economics and Building, 15(4), 1-15. DOI: http://dx.doi.org/10.5130/AJCEB.v15i4.4572

Corresponding author: Luke Daniel; Email - lukeadaniel01@gmail.com

Publisher: University of Technology Sydney (UTS) ePress 
injury rates within the workplace due to ill-conceived safety leadership behaviours. Neglecting to define safety leadership may contribute to invalid safety leadership efforts which may dissipate the strength of the overall safety on a project or site. This negative impact can be an immediate fiscal downfall but more importantly a moral and ethical dilemma if someone is injured on a worksite.

\section{Literature Review}

\section{General Leadership}

The broadness of general leadership is evident in the following definition that leadership is "The art of influencing people by persuasion or example to follow a line of action' (Durban, Dalglish and Miller, 2006, p.3). A plethora of research exists within the leadership arena that can be linked to the nuances of this research. In a recent review on leadership articles over the last decade (2000-2009), it was reported that the general field of leadership is more diverse, varied and complex than at any time in the previous few decades (Gardner et al., 2011). With the amount of information available, a narrowing of the literature is needed to focus on those elements that are pertinent towards the defining elements of safety leadership.

Previously, the management of construction projects has been linked to compliance and error prevention and leadership with prescriptive punishment served for safety violations (Podsakoff et al., 2006). This leadership approach has not been able to successfully minimise injuries or improve safety outcomes, as is evident through current injury rates within Australia (Safe Work Australia, 2012). As a result, a leadership discipline that encompasses safety through factors of influence such as engagement, ownership and relationships is needed (Leroy, et al., 2012). These elements are acutely recognised through the leadership disciplines of third generational leadership, transformational leadership, authentic leadership, charismatic leadership and the importance of leader-member exchange. In the context of this research, these disciplines will be labelled general leadership and will help shape the basis of safety leadership.

Third Generation Leadership was coined by Long (2013) with the behavioural components being rooted in the leader by being collaborative, commitment based and self-directed. These behaviours are underpinned by the psychology of the person having an internal locus of control. The underpinning of safety leadership can be through the neuroscience of locus of control and its components of reasoning and higher levels of learning. These are components of the neocortex (Long, 2013). Third-generational leadership can be transposed over individual safety with its nuances being built through transparency and empowerment.

The paradigm into transformational leadership has been dominant in the literature over the last 25 years and its practical offshoot has had a benign effect on employees and an organisation's performance (Judge and Piccolo, 2004). The markers of a transformational leader range from the articulation of strongly-held beliefs to an overall commitment to the organisation (Bass and Bass 2009). It was outlined by Mullen and Kelloway (2009) that there is a considerable lack of transformational based leadership interventions targeted towards safety within the leadership literature. This gap will be addressed through this research under the guise of defining safety leadership.

A recent spike in the literature pertaining to authentic leadership has become more prominent over the last decade (Gardner et al., 2011). Some early pioneering work by Kernis and Goldman (2006) outlined that authenticity is encompassed by awareness, unbiased processing and relational orientation. The orientation towards interpersonal relationships and deep selfunderstanding can create the edifice of strong organisational policy that is nurturing towards safety and the reporting of safety incidents. 
Existing literature suggests that charismatic leadership may be precipitated by a crisis or a time of distress (Trice and Beyer, 1986). Adding to this is further support that a crisis may be a facilitating but unnecessary requirement for charismatic leadership to emerge (Halverson, Murphy and Riggio, 2004). From a safety leadership perspective, a crisis could be anything that relates to the potential to cause harm or injury. As a result, the transition of a crisis which becomes an antecedent for charismatic leadership can also serve as the trigger for safety leadership.

Strong supervisor to employee relationships can be the foundation of leader-member exchange (LMX). The quality of such relationships has been shown to strongly influence employees' satisfaction in interpersonal, group and organisational contexts (Mueller and Lee, 2002). The role that leader-member exchange has within safety has been highlighted through work by Hofmann and Morgeson (1999). Results from their study showed that upward safety communication between team members and their supervisor can be related to adverse safety events. In follow up research by Kath, Marks and Ranney (2010) it was further detailed that the factors that influence leader-member exchange within the safety sphere included perceived management attitudes towards safety, and job-demands interfering with safety.

\section{Safety Leadership}

To set the scene of leadership as it relates to safety, it was detailed from the work of Long (2013) that the board of directors sets the tone of leadership through governance, whilst the chief executive officer (CEO) personalises the message with operational performance and the senior leadership team applies the strategy. The focus of this research will be built around the application of safety leadership with senior leaders as opposed to setting the governance or establishing organisational policy through the board of directors or CEO. This establishes a practical application in defining the behaviours that are evident in successful safety leaders within the construction environment.

The initial investigation of broader leadership studies as it pertains to safety was warranted through the research of Zanko and Dawson (2012). Conclusions from this research detailed that traditional occupational health and safety (OHS) has focused on policies and systems and there is a notable lack of research on OHS safety leadership behaviours. It was reported that OHS leadership is often lumped into the Human Resources (HR) field and further conceptual development is firmly needed. Safety leadership seems to be spoken of in the same breath as general leadership, without taking into account the nuances of safety. To assist in the stock-take and understanding of safety leadership, it is best to start with current research within this domain, to help establish the current paradigm that exists towards safety leadership.

A recent study into effective safety leadership defined the construct as 'the process of defining the desired state, setting up the team to succeed and engaging in discretionary efforts that drive the safety value' (Cooper, 2015, p.49). The details behind this definition were investigated and traced back to a website of a consulting company that offers services within the field of safety leadership. Their definition of safety leadership was neither research-based nor contextualised for the Australian construction environment. A lack of a clear definition is further reflected through other research by Read et al. (2010). They detailed the importance of safety leadership when engaging the workforce, although no clear definition of what safety leadership means was provided. A national Australian competency framework towards safety leadership was detailed by Biggs, Dingsdag and Roos (2008) who defined a range of safety terms and approaches to safety leadership, however failed to define safety leadership within the framework or as a standalone concept. There is a general sense that the definition of safety leadership is implied, innate or linked to broader leadership studies. 
In a study undertaken by $\mathrm{Lu}$ and Yang (2010), the impact of safety leadership upon safety behaviour was investigated within terminal operations. Safety leadership was defined within three main dimensions which included safety motivation, safety policy and safety concern. It was detailed that safety leadership is a sub-system of organisational leadership, where visible leadership behaviours provide opportunities for safety issues and concerns to be discussed. The findings from $\mathrm{Lu}$ and Yang (2010) are based upon specific components of safety leadership being pooled under transformational and transactional leadership. Deeper elements of safety, culture and safety systems appear to be negated when considering the wider construct of safety leadership and its uniqueness from other leadership fields.

Research conducted by Wu, Chen and Li (2008) investigated the impact that safety leadership has upon a company's safety climate and performance. Their definition and construct of safety leadership was established around safety caring, coaching and controlling. The inclusion of coaching has links within the field of relational leadership but was not detailed specifically towards safety. Their operational definition of safety leadership was borrowed from a safety leadership scale assessment, without an explanation of what safety leadership entails. Results from this study detailed that managers who demonstrate safety commitment positively influence safety performance with safety climate being the moderating component.

In a more recent meta-analytic review, safety leadership was explored under the guise of transformational and transactional leadership (Clarke, 2013). Results showed that transactional leadership is important in ensuring compliance with rules and regulations, whilst transformational leadership is associated with encouraging employee participation in safety. These elements were shown to have a mediating effect on safety culture. Further findings outlined suggestions for future theoretical development into the concept of safety leadership in order to explore leadership flexibility and its application within the safety domain.

The view that transactional safety leadership is warranted can be applied with some of the nonnegotiable elements of safety. This pertains to the compliance of minimum standards of work which employees need to adhere to, sometimes colloquially called 'lifesaving rules'. The context of transactional safety leadership within the construction industry may raise some challenges due to this approach being a remnant of the less mature environment.

The application of transactional leadership within the construction industry may serve as a continuation of the status quo and a remnant of the less mature environment. This is echoed by the research of O'Dea and Flin (2001) that outlined leaders within the resources sector have a predilection towards directive leadership and even with knowledge of effective leadership behaviours, still choose to be directive. This in turn has an impact on motivating and controlling some of the more crucial aspects of safety.

\section{Research Method}

\section{Ontology and Methodology}

The pendulum swing from a subjective to objective approach to social research can paint the overall research methodology of a study. The ontology, which explains that reality is a social construction, ties in well with the ontological nature of this research. Therefore this study is weighted towards a subjective approach to social science. Specifically, the research paradigm for this study can be cemented around an interpretivist/hermeneutics perspective. This perspective was formed on the notion that individuals and groups make sense of the world through their own individual experiences, memories and expectations (Flowers, 2009). Safety leadership would not be a moot point if we were living within a predictable concrete environment. In contrast to this is the richness of organisational culture and variables of the external environment, which can influence an individual's behaviour. 
A post-positivist approach was chosen for this topic due to the exploratory nature of the research and absence of a defined theory or descriptive foundation. A deeper understanding of how one views safety leadership was captured through in-depth interviews with a cross section of the senior leadership team. Leadership can be an abstract concept that is focused around influence and reach (Goleman, 2001). It is for this reason that safety leadership needed to be explored in more detail via the nodes of information discovery and the personal impact that safety leadership has upon an individual.

Adhering to the nature and integrity of exploratory research, this research was driven by the participant. The research questions were explored through a process of appreciative inquiry and well formulated questions through the free flow of conversation. The adage of expecting the unexpected lends its applicability to exploratory research. With the purpose of this research being rooted within exploratory means, the suitability of the correct data collection technique was astutely accounted for.

\section{Sampling}

To assist theoretical development, random sampling was forgone in order to target the population sample that is in the best position to influence employee behaviour. The scope of positional influence for each participant was deemed most suitable in unearthing the phenomenon investigated. Purposive sampling is best suited for exploratory research and such sampling can produce highly specific information from a population that could be challenging to reach (Neuman, 2011). Purposive sampling is also known as judgement sampling, in which individuals are selected based upon some personal judgement (Zikmund et al., 2010). This premise adds to the importance of interviewing the chosen sample size of leaders within the construction company.

The sampling of participants within this study included general managers (GM), project managers (PM), construction managers (CM) and health, safety and environment (HSE) managers. The inclusion of health, safety and environment managers was undertaken given their breadth of influence across all disciplines within a construction project and specialised skills within safety. With the selection of participants chosen, fertile ground for analysis can be established through alignment or misalignment across the leadership group, with common threads being highlighted.

To increase the transferability of key themes and exploration of safety leadership, the sample size was driven by data. A sample size of twenty participants were interviewed which included a total of five general managers, five project managers, five construction managers and five HSE managers. If data saturation did not occur with this sample size, more participants would have been interviewed. The sample size was taken from various projects across Australia within an Australian top-tier construction company that has over 5,000 employees. Interviews with the participants were undertaken at their place of work and within their environment, to aid ease and to increase comfort.

\section{Coding and Triangulation}

Two commonly adopted approaches to the coding of data can be classified as techniques of 'code and retrieve' and techniques relating to the 'emergence and interrogation' of data (Richards and Richards 1994, p.168). The coding and retrieving of data assists with managing data to predetermined categories whilst the emergence and interrogation technique assists in generating concepts from the information obtained (Gough and Scott, 2000). This research adopted a mix of the two techniques, generated by the literature and ontology of the researcher. For this study, there was an absence of computer programs that were utilised for coding. Instead, a focus on 
pre-coding categories was employed which acted as a foundation before further emergence and interrogation of data was employed.

Coding was conducted through the scope of the literature and themes developed from this research into safety leadership, with other categories being added for further analysis. Specifically, the categories were grouped into contained relationships where one category is contained into one larger category. The coding process was undertaken in three separate stages utilising different coding techniques in each stage. Each coding technique followed the sequenced methodology of Open Coding, Axial Coding and Selective Coding. This coding process can be broken down to the initial identifying of themes, assigning labels to themes and elaboration of major themes (Neuman, 2011). The data obtained went through a process of triangulation.

To harness a macro perspective, triangulation in this study was undertaken through selfreflection and peer-review of the data. Throughout the interviewing, transcribing and coding data process, this researcher underwent a process of self-reflexivity which included noting down any potential biases and thoughts throughout the coding process. The aim of this was to increase the accuracy and integrity of information, as detailed through the work of Guba and Lincoln (2008). Another by-product of self-reflexivity was to view the data from different perspectives. Data was further triangulated through peer review of the themes to aid inter-rater reliability and to objectively ascertain any biases noted. As recommended by Shenton (2004), a thick description of data was described to aid the transferability of information. This equated to direct quotes from participants to support any associated themes and help with the dependability of data.

\section{Results}

Across the sample size of twenty participants, the total years of experience within the construction industry was 387 years, with a mean average of 19.3 years. Total length of service within the company that this research was rooted within was 112.5 years with a mean average of 5.6 years. The average number of direct reports that the participants had was twelve. Each participant's first language was English. Specific experience and demographics according to job position have been detailed in Table 1.

Table 1: Mean Demographics based Upon Job Position

\begin{tabular}{|llll|}
\hline Position & $\begin{array}{l}\text { Years of } \\
\text { Experience }\end{array}$ & $\begin{array}{l}\text { Length of Service } \\
\text { within Company }\end{array}$ & $\begin{array}{l}\text { Number of } \\
\text { Direct Reports }\end{array}$ \\
\hline Construction manager CM) & 22.8 & 5.7 & 15 \\
\hline Project manager (PM) & 16.0 & 4.5 & 12.6 \\
\hline HSE manager (HSE) & 16.2 & 4.7 & 8.6 \\
\hline General manager (GM) & 22.4 & 8.8 & 11 \\
\hline
\end{tabular}

From the total sample size of participants, $10 \%$ were female (2) and $90 \%$ were male (18), with $65 \%$ (13) of the participants having previously worked outside of Australia in the construction industry. The gender imbalance highlighted in the above table is typical of the male-dominated construction and mining industry (Mayes and Pini, 2014). Both females in the sample size were project managers. 


\section{Safety Leadership v General Leadership}

Information gathered from the interviews revealed that the majority of participants believe that there is no difference between safety leadership and general leadership. This was governed by some of the following statements across all job positions: "not sure that I draw a distinction between safety leadership and leadership"; "I prefer not to discern between leadership and safety leadership ... I think if you're a good leader, you're good at all aspects of leadership and safety is no different". The main thoughts supporting this notion relate to the perception that safety is one of many elements to a business and that a good leader would be strong in all areas of the business. Other comments that further support this view point include: "Safety leadership is leadership in general, leading by example" and "that the problem with safety leadership is that we've divorced it from all types of leadership" and "regardless of the subject, the style of leadership should be the same". Adding to the notion that safety leadership and leadership should be synonymous is the following comment from a GM that stated if safety leadership exists then it is "owned by the safety department, rather than owned by leadership and the business".

Findings indicated that the core similarities between general leadership and safety leadership are constituted by the behaviours of acting with integrity, being able to influence and "the whole human element in terms of how sincere the leader is and are they a good communicator". Weak support was gathered that detailed the unique characteristics that make up safety leadership, although the elements raised are pivotal in their distinction.

\section{Unique Components of Safety Leadership}

The viewpoint that safety leadership is a separate category from leadership reached a minority consensus, with unique elements being highlighted which included transparency, wellbeing and the promotion of safety. Further to this, safety leadership was seen as "driving the safety message out on site and doing everything the right way", "about saving someone potentially" and "setting the safety standard and being visible on what's acceptable, not acceptable". Further findings supporting the distinction of safety leadership included the possibility that "you can be a very good leader, without being a good safety leader", which was attributed to one's own conduct and how they personally manage and promote safety.

Other opinions on safety leadership outlined that "safety leadership goes further through your organisation" and "there's the guidelines and the rules" which is a core distinction with safety in the Australian construction environment. This cascades to other supporting viewpoints from the data, which outlines the priority of safety. One PM stated that, with safety issues, "you've got to show that as a safety leader, that it's got to be dealt with above and beyond anything else" with one CM sharing that "everyone's got a role in safety on site" and this is how safety leadership differs from general leadership. The above outlined intricacies of safety leadership may warrant its separation from general leadership disciplines.

\section{Defining Safety Leadership}

Results fed into the notion that safety leadership is an ill-defined concept which was reflected in one GM saying that "when I think about safety leadership, I tend to think about leadership in general, maybe that's just because there just isn't enough definition of what safety leadership is". When participants were asked to define safety leadership, core factors of accountability, "walking the talk" and "leading by example" was present across all job positions. Accountability was referenced through the "outlining of expectations" and "being accountable for safety". Branching from these components was a strong reference about personal value towards safety which was highlighted by one PM saying 'it's not just there at the coalface, it's everywhere. It's at 
home; it's in your personal life". This was further expanded upon by another PM saying that safety leadership is "not something that you're trained in ... I think its values".

When participants were defining safety leadership, aspects of safety management were often quoted. This was in relation to abiding by the safety absolutes, with one PM saying it is about "making sure they have the right tools and resources" whilst accounting for all aspects of planning and organising. These findings are further elaborated on under a separate category pertaining to safety management and statistics. The definition of safety leadership also yielded findings that are spoken of in the same realms as general leadership. This included the importance of "empowering others", "mentoring type role" and "to be adaptable and change the situation you're in". This was echoed by one HSE manager saying, "I use the old business model of situational leadership". The importance of integrity and transparency was also commonly discussed as core components in safety leadership. Supporting findings of transparency included such comments from an HSE manager who stated "it's probably a lot more transparent", and one CM saying that it is about "addressing all issues, not just palming them off". Further defining and exploration of safety leadership was heavily aligned to the components of establishing relationships and being authentic in one's approach.

Discrepancies did exist between safety leadership and general leadership; however common ground was established between the core characteristics of safety leadership. A penchant towards demonstrated behaviours was often cited through such expressions as "leading by example" and "setting the example". Other common elements were in relation to personal values to safety, empathy and the ability to influence others to undertake work safely and a degree of empathy, which can help foster working relationships.

\section{Safety Leadership differences Between Job Positions}

Across the sample size of participants, there were more similarities between the job roles compared to differences in regard to the topic of safety leadership. The majority of differences were mainly predicated by the amount of data collected upon a theme as well as the depth of examples and agreed scope of definition with safety leadership.

Across the general managers, there was more of an elaborated reference to the broader context of safety leadership and its application across the Australian construction industry. All of the general managers viewed safety leadership and leadership as being synonymous with each other, with generalised comments being made in reference to a safety vision. These differences may be generated around the scope of influence a general manager has upon the business and the lumping of safety as a by-product of leadership.

In comparison, the data collected from project managers had a particular emphasis on costs and client expectations. A few project managers saw a distinction between safety leadership and general leadership. Examples of this included the transparency of safety, matched with the juggling of compliance-based requirements with safety management systems.

Construction managers made fewer comments about safety statistics and shared more practical examples of engagement with the workforce. This was outlined through the amount of time each construction manager spends "in the field", which also reflected their emphasis on relationship building. Construction managers within the sample size often reached their position by "rising through the ranks" and coming from a trade background. This historical connection might leverage the importance of connectedness in the field. With construction managers, there was more of a weighting towards safety leadership being a separate discipline from broader leadership. 
The importance of relationship building was jointly emphasised by HSE managers, as well as a focus on safety leadership behaviours that were more aligned with managerial tasks. HSE managers also noted more challenges associated with safety leadership compared to their research counterparts. From these findings, the maturation of safety leadership and its distinguishing factors from general leadership can be mapped upon a continuum of scope and responsibility. From the findings it appears that the more responsibility one has, the broader safety leadership becomes, where it eventually gets lumped into general leadership. This progression has been mapped out in Figure 2.

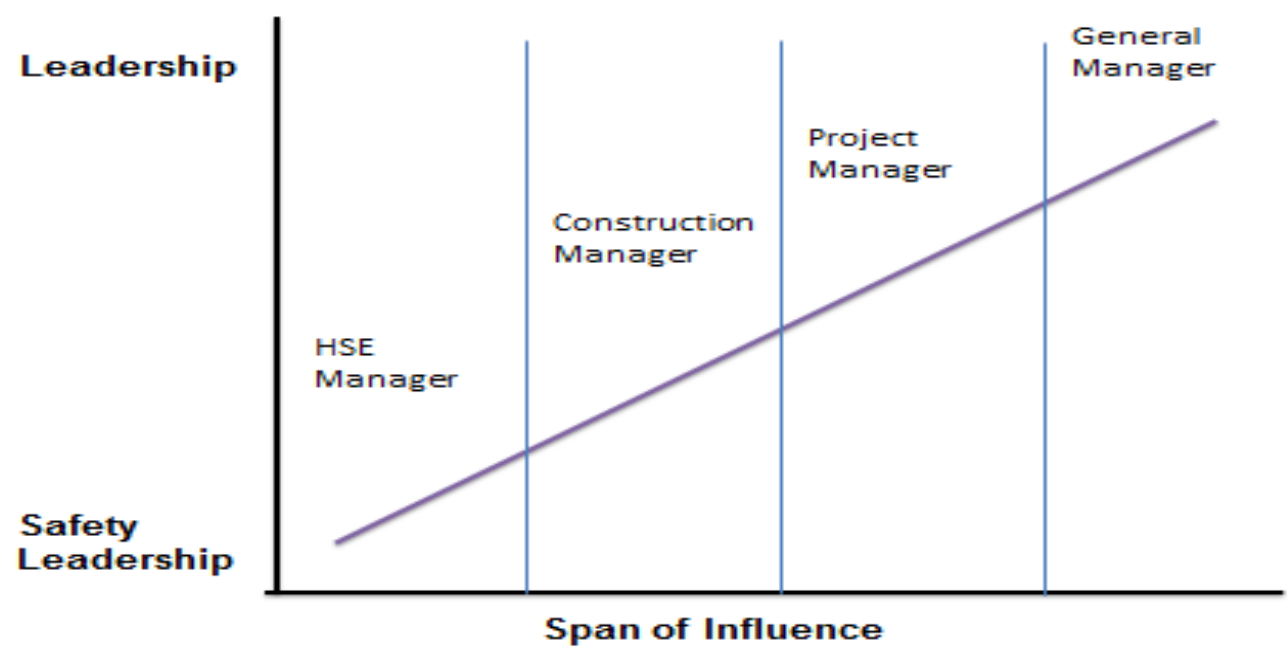

Figure 2: Safety Leadership between Job Positions

\section{Discussion}

The discourse into the definition of safety leadership was explored through the research findings of this study. Findings indicated the parallel relationship that safety leadership has with general leadership. Such parallels were evident via the importance of transparency when sharing safety information and being open and honest when sharing information which echo the tenets of authentic leadership (Gardner et al., 2011). The importance of engagement with safety leadership was reflected through specific language, rhetoric, stories and metaphors being used when describing safety. These findings are akin to research completed within the arena of charismatic leadership (Davis and Gardner, 2012). It can be concluded from this research that safety leadership dabbles within different branches of leadership but is centred within a safety context, from a legislative and moral framework. This context was evident through the constant mentioning of management systems when participants were describing safety leadership behaviours.

\section{Safety Leadership within Leadership}

The viewpoint shared by many participants is that safety leadership was no different from the broader aspects of leadership, which was validated through a pure linguistic and outcome perspective. The common context and objective of safety leadership could be the absence of injury or harm to employees. As findings from this research suggest, safety leadership is more "visible" and "tactile" and pertains more towards securing the wellbeing and health of others. These distinguishing aspects have elements of corporate social responsibility (CSR) written all 
over them, which is often characterised by the moral obligation to act in the interests of others and society as a whole with the purpose of harm reduction (Massin, 2012).

The importance of CSR is getting more public screening through the acceptance of whistle blowers and promotion of ethical conduct. Despite this, there is no separate branch of leadership component called CSR leadership which would have similar conscripts to safety leadership based upon moral outcomes. The objective in leadership may be fixated on a group collective or goal, which may allow such moral scriptures to be jettisoned for the achievement of a goal. Past political leaders such as Hitler and Stalin showed leadership through the achievement of goals, although arguably in the absence of a moral conscience or a result of ignoring their conscience. Safety leadership from this perspective could be demonstrated through the absence of harm and promotion of safety towards others, although this may contrast with other organisational goals of the leader.

The factors that differentiate safety leadership from other forms of leadership start to emerge when the beam is magnified on one's personal regard to safety and the safety of others. The distinguishing factors of transparency also start to divorce safety leadership from general leadership. Findings indicated that one could be transparent with all elements of safety, where in other parts of the business one cannot. One project manager commented that all information relating to safety could be shared barring any identifying information for people involved in incidents.

When there is a safety process that identifies names for safety non-conformances, employee trust and engagement may be adversely impacted (Geller, 2008). Findings in this research outlined that safety leadership is most apparent in the field and is something that can be easily demonstrated. This context of safety leadership as a separate branch of leadership has been graphically represented in Figure 3 which has been based upon the core themes obtained from the data collected.

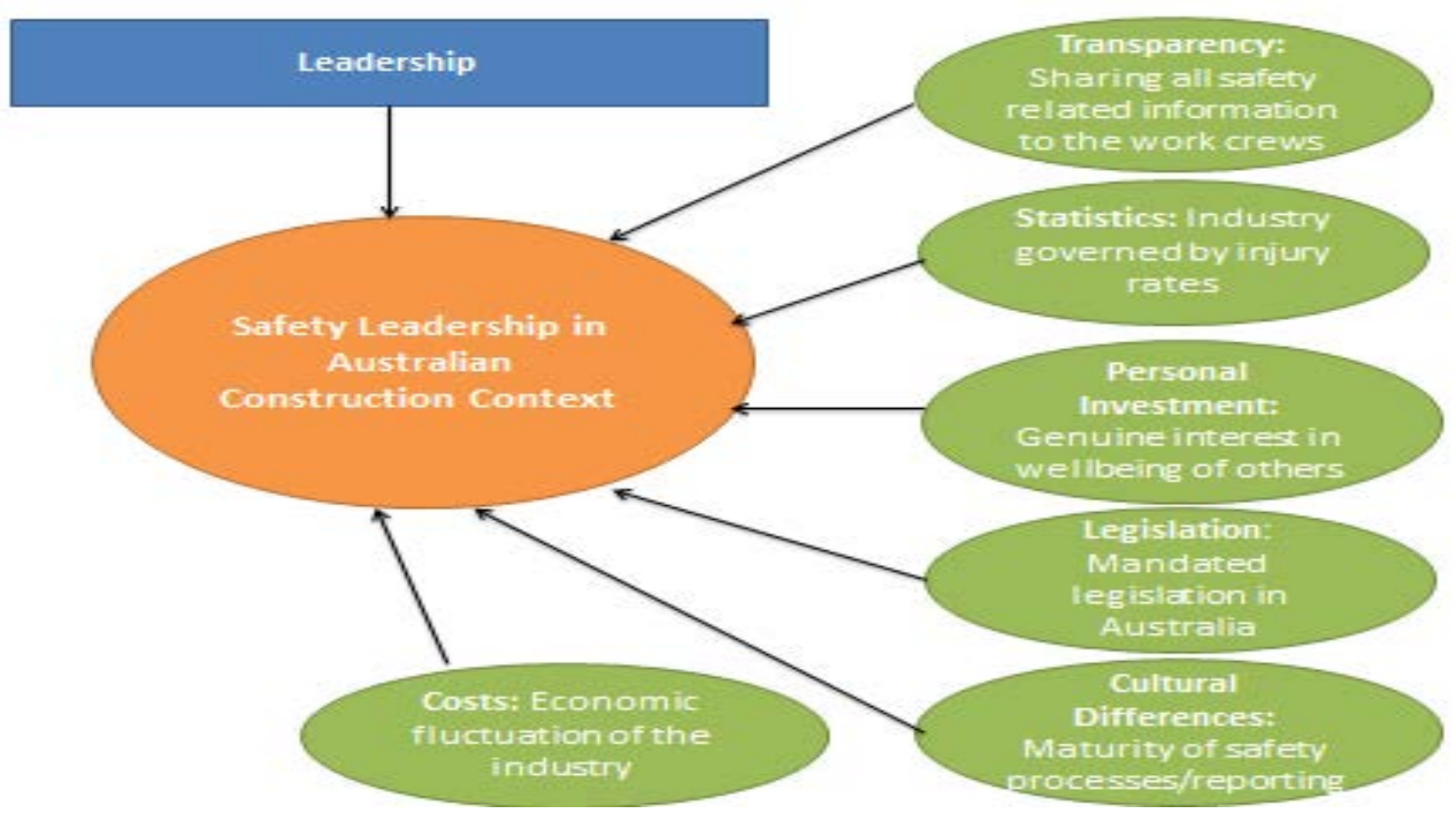

Figure 3: Context of Safety Leadership within current Operating Environment 


\section{Defining Safety Leadership}

The results from this study have given clarity and scope to the research question of: How do leaders within the construction environment define safety leadership and how does safety leadership differ from general leadership disciplines? The majority of participants used common colloquialisms such as "walking the talk". The inability of participants to provide a well-defined construct mirrors the findings of Zanko and Dawson (2012) who found that safety leadership was being lumped under the human resources discipline. Through the collation of quotes, themes and comments, a defined definition of safety leadership was developed. This definition incorporates language that reflects the importance of demonstrating safe behaviours, whilst outlining aspects of general leadership studies and the importance of personal values as detailed in the results. From the research collected, safety leadership has been defined as:

The demonstration of safety values through the creation of a vision and the promotion of wellbeing through the art of engagement, bonesty and discipline.

This definition has been crafted through a conscious choice in language used by participants and empirical findings from this research. The concluding definition was shared with each participant, post interview for further consultation and discussion. There was universal acceptance and agreement towards the definition in providing clarity around the topic as well as serving as a tool for future developmental programs. Key components of this definition have been detailed in Figure 4 and have been described below.

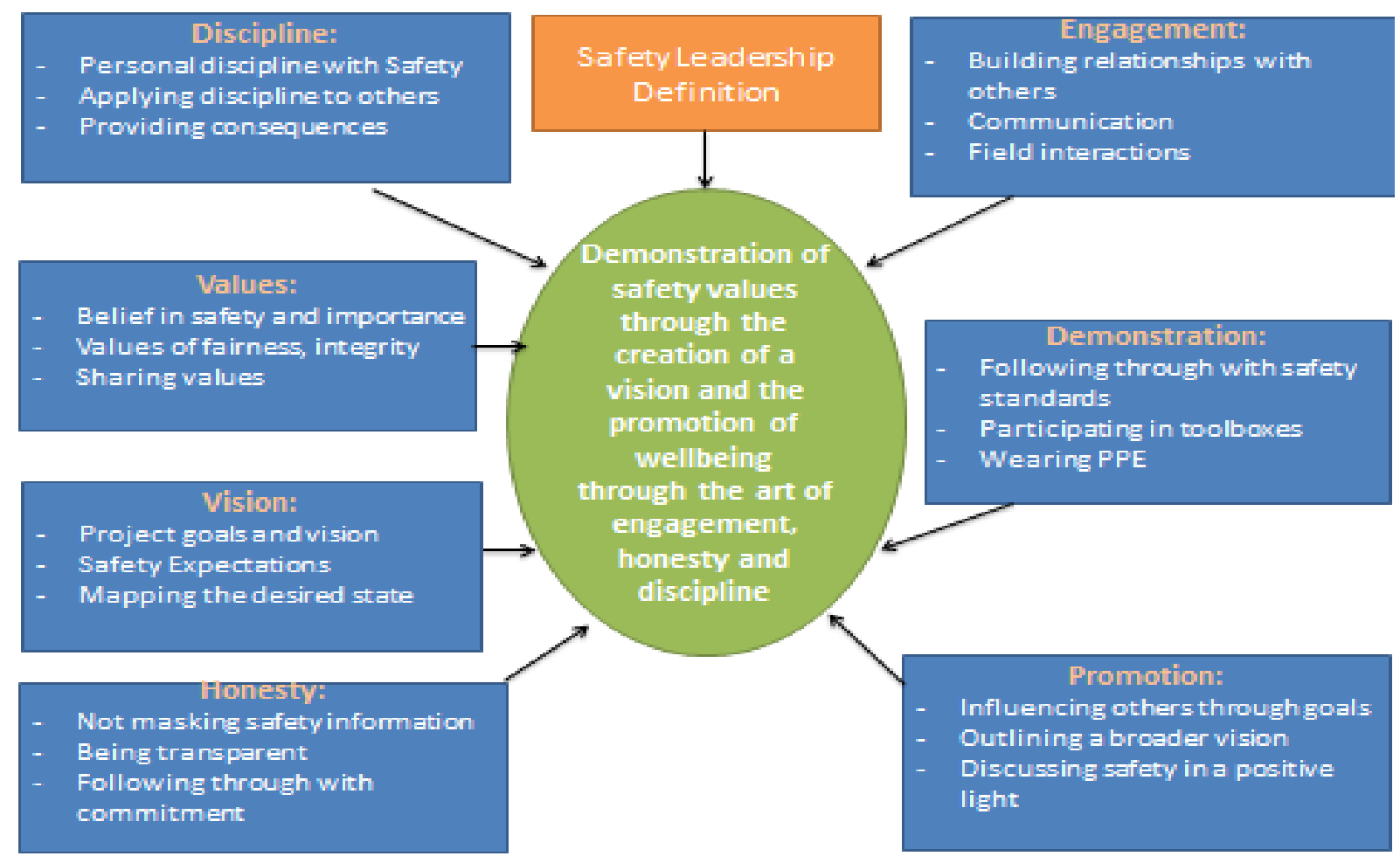

Figure 4: Integral Components to the Definition of Safety Leadership

Components that make up the definition have been sourced directly from core themes but also mirrored by supporting research. The importance of tactility and the demonstration of displaying safe behaviours were often cited by participants. This importance of tactility on influencing safety was reflected in the work by Luria and Morag (2012), who found that safety management by walking around increased safety performance and worker morale. The benefit of leadership engagement with the workers has been demonstrated and replicated multiple times (Conchie, Moon and Duncan, 2013) and outlined through this research study via the importance of 
building relationships. The engagement with employees is the pathway to developing robust safety conversations facilitated by effective communication and safety behaviours such as delivering toolboxes, carrying out risk assessments or participation in incident investigations (Biggs and Biggs, 2013).

Discipline as applied in the safety leadership definition can have a double loaded meaning. Discipline can be a reference to ensuring that people are accountable for their work through the application of suitable consequences. The other application for discipline is through selfdiscipline with regard to the following of safety obligations. Such discipline can become a hallmark of consistency, which helps in developing trust (Conchie, Taylor and Charlton, 2011). Results from this study outlined the importance of adhering to safety management processes whilst applying discipline to employees who disregard safety.

Being able to influence others is a key component in safety leadership and is aligned with the promotion of safety through the ability to influence others. The findings in this study outlined that the best way to influence safety as a leader is by "being in the field". This is crystallised by the interpersonal strengths of influencing others through the variables of communication, selfassurance and the ability to win others over (Rath and Conchie, 2008). These research findings outlined the importance of values in safety leadership. Specifically, this was voiced by a personal belief in safety as well as empathy for others.

The values of a safety leader are also linked to the honesty of the individual, and this was quoted multiple times through such comments as being "genuine" and being "transparent". Components of honesty have been linked with existing research on authentic leadership (Hsiung, 2012). This study outlined that the common goal of participants was to ensure that each worker goes home safely and that this acts as a broader vision.

\section{Conclusion}

The differentiating factors between safety leadership and general leadership have been dissected, with a suitable definition being grounded on the findings of this research. Safety leadership has its unique variables established by the operating environment that it exists within and therefore differs from other leadership models. The implication of such findings, allows a more viable discourse into the area of safety leadership which may minimise confusion and lack of clarity around the topic.

Findings can kick start the separate discipline of safety leadership, which therefore holds its own unique differences based upon such elements as vision, values and demonstration of behaviours. The separation of how safety leadership differs from other disciplines is one of the key contributing factors from this study. With an empirical definition being detailed, future safety leadership programs can be cross-mapped for validity and linked to behaviours emanating from this definition and help reduce work related incidents.

The detailed definition of safety leadership may serve as a foundation for other industries such as mining, manufacturing or petrochemicals. The operating environment across the industries may slightly differ, although the safety leadership factors detailed in the definitions may still ring true. Further confirmatory research outside the Australian construction industry can expand upon these results. 


\section{References}

Bass, B.M. and Bass R., 2009. Bass Handbook of Leadership: Theory, Research and Managerial Applications. 4th ed. New York: Free Press.

Biggs, H.C. and Biggs, S.E., 2013. Interlocked projects in safety competency and safety effectiveness indicators in the construction sector. Safety Science, 52(1), pp.37-42. doi: http://dx.doi.org/10.1016/j.ssci.2012.03.014

Biggs, H.C., Dingsdag, D.P. and Roos, C.R., 2008. A practical guide to safety leadership: Implementing a construction safety competency framework. Cooperative Research Centre for Construction Industry, Brisbane: IconNet.

Clarke, S., 2013. Safety leadership: A meta-analytic review of transformational and transactional leadership styles as antecedents of safety behaviours. Journal of Occupational and Organisational Psychology, 86(1), pp.22-49. doi: http://dx.doi.org/10.1111/j.2044-8325.2012.02064.x

Conchie, S.M., Moon, S. and Duncan, M., 2013. Supervisors' engagement in safety leadership: Factors that help and hinder. Safety Science, 51(1), pp.109-17. doi: http://dx.doi.org/10.1016/j.ssci.2012.05.020

Conchie, S.M., Taylor, P.J. and Charlton, A., 2011. Trust and distrust in safety leadership: Mirror reflections? Safety Science, 49(8-9), pp.1208-14. doi: http://dx.doi.org/10.1016/i.ssci.2011.04.002

Cooper, D., 2015. Effective safety leadership. Professional Safety, 60(2), pp.49-53.

Davis, K.M. and Gardner, W.L., 2012. Charisma under crisis revisited: Presidential leadership, perceived leader effectiveness, and contextual influences. The Leadership Quarterly, 23(5), pp.918-33. doi: http://dx.doi.org/10.1016/j.leaqua.2012.06.001

Durban, A.J., Dalglish, C. and Miller, P. 2006. Leadership. Milton: John Wiley and Sons Australia.

Flowers, P. 2009. Research philosophies - importance and relevance. MSc by Research. Cranfield School of Management.

Gardner, W.L., Cogliser, C.C., Davis, K.M. and Dickens, M.P., 2011. Authentic leadership: A review of the literature and research agenda. The Leadership Quarterly, 22(6), pp.1120-45. doi: http://dx.doi.org/10.1016/j.leaqua.2011.09.007

Geller, S.E. 2008. Leading People-based Safety: Enriching Your Culture. Coastal Training Technologies Corp, Virginia Beach.

Goleman, D., 2001. What makes a leader? Harvard Business Review on: What Makes a Leader? Boston: Harvard Business School Publishing Corporation.

Gough, S. and Scott, W., 2000. Exploring the purposes of qualitative data coding in educational enquiry: Insights from recent research. Educational Studies, 26(3), pp.339-54. doi: http://dx.doi.org/10.1080/03055690050137141

Guba, E.G. and Lincoln, Y.S., 2008. Paradigmatic controversies, contradictions and emerging confluences. In: N.K. Denzin and Y.S. Lincoln, eds. The Landscape of Qualitative Research. Thousand Oaks: Sage Publications. pp. 25586.

Halverson, S.K., Murphy, S.E. and Riggio, R.E., 2004. Charismatic leadership in crisis situations: A laboratory investigation of stress and crisis. Small Group Research, 35, pp.495-514. doi: http://dx.doi.org/10.1177/1046496404264178

Hashim, I.N. and Chileshe, N., 2012. Major challenges in managing multilpe project environment (MPE) in Australia's construction industry. Journal of Engineering, Design and Technology, 10(1), pp.72-92. doi: http://dx.doi.org/10.1108/17260531211211890

Hofmann, D.A. and Morgeson, F.P. 1999. Safety-related behaviour as a social exchange: The role of perceived organisational support and leader-member exchange. Journal of Applied Psychology, 84(2), pp.286-96. doi: http://dx.doi.org/10.1037/0021-9010.84.2.286

Hsiung, H.H., 2012. Authentic leadership and employee voice behavior: A multi-level psychological process. Journal of Business Ethics, 107(3), pp.349-61. doi: http://dx.doi.org/10.1007/s10551-011-1043-2 
Judge, T.A. and Piccolo, R.F., 2004. Transformational and transactional leadership: A meta-analytic test of their relative validity. Journal of Applied Psychology, 89, pp.755-68. doi: http://dx.doi.org/10.1037/0021$\underline{9010.89 .5 .755}$

Kath, L.M., Marks, K.M. and Ranney, J., 2010. Safety climate dimensions, leader-member exchange, and organizational support as predictors of upward safety communication in a sample of rail industry workers. Safety Science, 48, pp.643-50. doi: http://dx.doi.org/10.1016/i.ssci.2010.01.016

Kernis, M.H. and Golfman, B.H., 2006. A multicomponent conceptualization of authenticity: Theory and research. Advances in Experimental Social Psychology, 38, pp.283-357. doi: http://dx.doi.org/10.1016/S00652601(06)38006-9

Leroy, H., Dierynck, B., Anseel, F., Simons, T., Halbesleben, J.R., McCaughey, D., Savage, G.T. and Sels, L., 2012. Behavioral integrity for safety, priority of safety, psychological safety, and patient safety: A team-level study. Journal of Applied Psychology, 97, pp.1273-81. doi: http://dx.doi.org/10.1037/a0030076

Long, D.G., 2013. Delivering High Performance: The Third Generation Organisation. Farnham: Gower Publishing Limited.

Lu, C.S. and Yang C.S., 2010. Safety leadership and safety behavior in container terminal operations. Safety Science, 48(1), pp.123-34. doi: http://dx.doi.org/10.1016/j.ssci.2009.05.003

Luria, G. and Morag, I., 2012. Safety management by walking around (SMBWA): A safety intervention program based on both peer and manager participation. Accident Analysis and Prevention, 45(1), pp.248-57. doi: http://dx.doi.org/10.1016/j.aap.2011.07.010

Massin, S., 2012. Is harm reduction profitable? An analytical framework for corporate social responsibility based on epidemic model of addictive consumption. Social Science and Medicine, 74(12), pp.1856-63. doi: http://dx.doi.org/10.1016/j.socscimed.2012.02.006

Mayes, R. and Pini, B., 2014. The Australian mining industry and the ideal mining woman: Mobilizing a public business case for gender equality. Journal of Industrial Relations, 56(4), pp.527-46. doi: http://dx.doi.org/10.1177/0022185613514206

Mueller, B.H. and Lee, J., 2002. Leader-member exchange and organisational communication satisfaction in multiple contexts. The Journal of Business Communication, 39(2), pp.220-44. doi: http://dx.doi.org/10.1177/002194360203900204

Mullen, J.E. and Kelloway, E.K., 2009. Safety leadership: A longitudinal study of the effects of transformational leadership on safety outcomes. Journal of Occupational and Organisational Psychology, 82(2), pp.253-72. doi: http://dx.doi.org/10.1348/096317908X325313

Neuman, W.L., 2011. Social Research Methods: Qualitative and Quantitative Approaches. Boston: Pearson.

O'Dea, A. and Flin, R., 2001. Site managers and safety leadership in the offshore oil and gas industry. Safety Science, 37(1), pp.39-57. doi: http://dx.doi.org/10.1016/S0925-7535(00)00049-7

Podsakoff, P.M., Bommer, W.H., Podsakoff, N.P. and Mackenzie, S.B., 2006. Relationships between leader reward and punishment behavior and subordinate attitudes, perceptions, and behaviors: A meta-analytic review of existing and new research. Organisational Behavior and Human Decision Processes, 99(2), pp.113-42. doi: http://dx.doi.org/10.1016/j.obhdp.2005.09.002

Rath, T. and Conchie, B., 2008. Strengths Based Leadership. New York: Gallup Press.

Read, B.R., Zartl-Klik, A., Veir, C., Samhaber, R. and Zepic, H., 2010. Safety Leadership that engages the workforce to create sustainable HSE performance. SPE International Conference on Health, Safety and Environment in Oil and Gas Exploration and Production. Rio de Janeiro, Brazil, pp.1-18. doi: http://dx.doi.org/10.2118/126901-MS

Richards, I.L. and Richards T., 1994. From filing cabinet to computer. In: Bryman, A. and Burgess, R.G., eds. Analysing Qualitative Data. New York: Routledge. pp. 146-72. doi: http://dx.doi.org/10.4324/9780203413081 chapter 8

Safe Work Australia, 2012. Key Work Health and Safety Statistics, Australia. [online] Available at: <http://www.safeworkaustralia.gov.au/sites/swa/about/publications/pages/key-whs stats-2012> [Accessed 18 November 2013].

Shenton, A.K., 2004. Strategies for ensuring trustworthiness in qualitative research projects. Education for Information, 22(2), pp. 63-75. 
Trice, H.M. and Beyer, J.M., 1986. Charisma and its utilisation in two social movement organizations. Research in organizational behaviour, 8, pp.113-64.

Wu, T.C., Chen, C.H. and Li, C.C., 2008. A correlation among safety leadership, safety climate and safety performance. Journal of Loss Prevention in the Process Industries, 21(3), pp.307-18. doi: http://dx.doi.org/10.1016/j.jlp.2007.11.001

Zanko, M. and Dawson, P., 2012. Occupational health and safety management in organisations: A review. International Journal of Management Reviews, 14(3), pp.328-44. doi: http://dx.doi.org/10.1111/j.14682370.2011.00319.x

Zikmund, W.G., Babin, B.J., Carr, J.C. and Griffin, M., 2010. Business Research Methods. Mason: South-Western Cengage Learning. 